\title{
The MiniArc sling for female stress urinary incontinence: clinical results after 1-year follow-up
}

\author{
C. R. C. Hogewoning • I. M. C. Ruhe • M. D. Bekker • \\ C. J. A. Hogewoning $\cdot$ H. Putter $\cdot$ M. C. DeRuiter • \\ R. C. M. Pelger $\cdot$ H. W. Elzevier
}

Received: 12 June 2011 / Accepted: 28 October 2011 / Published online: 23 November 2011

(C) The Author(s) 2011. This article is published with open access at Springerlink.com

\begin{abstract}
Introduction and hypothesis The objective of this study was the assessment of the efficiency of the MiniArc for curing stress urinary incontinence.

Methods Seventy-seven patients, operated on from March 2008 to November 2009, were evaluated in this study. Oneyear post-operative data are presented. All patients suffered from predominant stress urinary incontinence. After 1 year, response was $74 \%$. Evaluation was performed using a questionnaire consisting of the EuroQol-5 Dimensions, the Patient Global Impression of Improvement, the Incontinence Impact Questionnaire, the Urinary Distress Inventory, the Prolapse/Urinary Incontinence Sexual Questionnaire, short form, and the Defecation Distress Inventory.
\end{abstract}

C. R. C. Hogewoning $(\bowtie) \cdot$ M. D. Bekker $\cdot$ R. C. M. Pelger H. W. Elzevier

Department of Urology, Leiden University Medical Center, P.O. Box 10392, 2300 WB Leiden, The Netherlands

e-mail: c.r.c.hogewoning@lumc.nl

I. M. C. Ruhe

Department of Obstetrics and Gynecology, Flevo Hospital,

Almere, The Netherlands

C. J. A. Hogewoning

Department of Obstetrics and Gynecology,

Albert Schweitzer Medical Center,

Dordrecht, The Netherlands

H. Putter

Department of Medical Statistics and Bioinformatics,

Leiden University Medical Center,

Leiden, The Netherlands

M. C. DeRuiter

Department of Anatomy and Embryology,

Leiden University Medical Center,

Leiden, The Netherlands
Results One year after surgery, $68 \%$ of the patients stated an improvement in their incontinence status, while only $44 \%$ stated to be completely dry.

Conclusion The 1-year follow-up suggests that the MiniArc is less effective in the treatment of stress urinary incontinence than the TVT.

Keywords Quality of life · Questionnaires · Stress urinary incontinence $\cdot$ Suburethral sling

\section{Introduction}

It is estimated that urinary incontinence (UI) affects 10 $40 \%$ of the female population aged 15-64 years and has an even higher incidence after 65 years of age [1-3]. UI is defined as the uncontrolled and involuntary leakage of urine [4] and is associated with a reduction in quality of life (QoL) for women of all ages [1-3]. To assess this reduction, QoL questionnaires are commonly used and focus on the consequences of urinary incontinence [5-9]. Stress urinary incontinence (SUI) is described as urinary incontinence following increase of abdominal pressure as in sneezing or coughing and is due to a weakening of the muscles and connective tissue of the pelvic floor.

The wide acceptance of surgery with mid-urethral slings (MUS) as intervention for SUI is due to the effectiveness, rapidity, and minimal invasiveness of the techniques so far. After the first-generation (the tension-free vaginal tape, TVT) and second-generation (the trans-obturator tape, TOT, and the tension-free vaginal tape-obturator, TVT-O) tapes, the industry developed third-generation vaginal tapes, the MiniArc (introduced in 2007 by American Medical Systems) and TVT-Secur (introduced in 2006 by Women's Health \& Urology, Ethicon, Johnson \& Johnson). The TVT, 
TVT-O, and the TOT all show cure rates ranging from $84 \%$ to $100 \%$ after a minimum follow-up of 1 year [10].

The MiniArc uses self-fixating tips and is performed with a single incision in the anterior vaginal wall. With this design, the procedure aims to accomplish minimal tissue damage by lowering the number of incisions from three to one. Also, needle penetration of the obturator foramen or the retropubic space is avoided, thereby minimizing tissue and (potential) organ damage.

Studies of the MiniArc [11-18] show a variance in success rate (range, 69.1-91.4\%), after a minimum followup of 1 year. Although these studies all assess cure rate of the MiniArc, only the articles of De Ridder et al. and Pickens et al. [11, 18] discuss the impact on everyday functioning and QoL.

It is important to mention that no restrictions were made regarding the study population on the base of severity of SUI, age, BMI, etc. The aim of this study is to perform a 1-year post-operative evaluation of the treatment of SUI using the MiniArc sling with a focus on the efficacy, quality of life, and daily functioning.

\section{Material and methods}

A prospective study was performed at the Department of Gynecology of the Flevo Hospital, Almere. In this hospital, 77 primary interventions with the MiniArc were performed by one gynecologist (IMC) from March 2008 to November 2009.

The patient population consisted of women aged 2982 years who all had clinically established predominant SUI. If a patient was suspected of having urge incontinence due to detrusor overactivity, full urodynamics were performed. In the case of identified detrusor instability, the patient was subsequently excluded from the study. Patients were asked to complete questionnaires pre-operatively and 1 year post-operatively.

Inclusion criteria were predominant SUI and a minimum follow-up of 1 year post-surgery. Exclusion criteria were predominant urge incontinence and previous surgery for SUI.

It is important to mention that the tape was positioned against the urethra without compression, but the overall placement of the MiniArc was tighter than the traditional MUS. This study was approved by the medical ethics review board of the Flevo Hospital, Almere.

\section{Outcome}

Failure of the procedure was defined as persistent SUI, stated by the patient in the questionnaire as loss of urine upon exertion, coughing, or sneezing. Patients not reporting any amount of leakage were considered cured. A post- voidal residual volume of $150 \mathrm{ml}$ was considered as the maximum acceptable and treated with Ubretid (5 mg/day) and/or (self) catheterization.

\section{Questionnaire}

The questionnaire used has been validated by the Dutch Association for Obstetrics and Gynecology in cooperation with the Dutch Association of Urology to evaluate the impact of urinary incontinence. The questionnaire consists of 47 multiple choice questions and is divided in five sections that evaluate physical condition (health status), micturition status, defecation status, coping of the patient (emotional status), and sexual functioning.

The first part consists of the 5-Dimensional EuroQol instrument (EQ-5D) [19]. The EQ-5D is specifically designed to evaluate five different subcategories of the patient's current physical condition (mobility, self-care, daily activities, pain/complaints, mood) and is scored from 1 (no complaints) to 3 (serious complaints). The first part also includes a Visual Analog Scale (VAS), as well as a QOL scale to evaluate the overall health status of the patients.

The next parts evaluate the micturition status using the Urogenital Distress Inventory (UDI) [7], the coping behavior of the patients using the Incontinence Impact Questionnaire (IIQ) [7], and the defecation status using the Defecation Distress Inventory (DDI) [20]. The final part assesses sexual functioning with sections of the Pelvic Organ Prolapse/ Urinary Incontinence Sexual Questionnaire-SF (PIS-Q short form, limited to five questions [21]). The IIQ and UDI were scored using the different domains as described by v/d Vaart et al. [9].

The post-operative questionnaire was identical to the preoperative questionnaire except for the first question which assessed the improvement/deterioration post-surgery with the Patient Global Impression of Improvement (PGI-I) [22].

\section{Statistical analysis}

Results of both pre- and post-operative questionnaires were scored, and for the UDI, IIQ, and DDI, outcomes were converted in a scale ranging from 0 to 100 (higher= negative). Statistics were performed in SPSS release 17 (SPSS Inc., Chicago, IL, USA). $P$ values $<0.05$ were considered statistically significant. For multiple comparisons, a Bonferroni correction was conducted after the paired sample $T$ test.

\section{Results}

All patients screened for SUI and eligible for surgery with the MiniArc were asked to participate in our study and 
complete the pre-operative questionnaires. Of the operated patients, 77 filled in the pre-operative questionnaire and were thus eligible to be included in this study. Clinical characteristics of this patient group are described in Table 1.

After 1 year, these 77 patients were sent a copy of the post-operative questionnaire of which 57 were returned (74\%). No differences were found in baseline characteristics between responders and non-responders. Of the 77 patients who had primary surgery with the MiniArc, 10 $(13 \%)$ were anesthetized locally and 67 (87\%) had general anesthesia.

Complications were seen in 6 of 77 patients $(8 \%)$ and resulted in one cleaving of the MiniArc due to deteriorating urge incontinence. Other complications were dehiscence of the wound (one patient) and a large residue (two patients, $300-600 \mathrm{ml}$; two patients, $150-300 \mathrm{ml}$ ). At the 6 week check, all patients had normal emptying of their bladder. Further investigation showed that the dehiscence was due to a post-surgery hematoma and did not cause any problems after the first week. Success and complications over time are visualized in Table 2.

One-year post-surgery, $44 \%$ of the patients stated to be completely continent (Table 3). The patient's subjective satisfaction was scored ranging from "very much better" to "very much worse," using the PGI-I. After 1 year, $68 \%$ of the patients rated their current situation as either being "very much better" or "much better." The other $32 \%$ stated little improvement or even deterioration of their SUI in comparison to their pre-operative status (Table 3).

Pre-operatively, overall QoL mean score was 4.6 with a standard deviation of 0.9. One year after surgery, the QoL did not differ from pre-surgery. The VAS did also not differ significant 1 year after surgery.

The EQ-5D score did not show significant difference with pre-operational status. The part of the questionnaire concerning the micturition status was scored using the UDI (five subcategories). After 1 year, all five subcategories showed an improvement (Table 4).

Table 1 Clinical characteristics of patients treated with the MiniArc, $n=77$

\begin{tabular}{ll}
\hline Age & $52.1 \pm 12.6$ (range, 29-80) \\
BMI & $28.2 \pm 6.1$ (range, 17, 63-50, 43) \\
Parity & $2.3 \pm 0.9$ (range, 1-6) \\
None & $4(5 \%)$ \\
$1-3$ & $68(88 \%)$ \\
$4,>4$ & $5(7 \%)$ \\
Education & $3.4 \pm 1.7$
\end{tabular}

Values are given as mean $\pm \mathrm{SD}$ or percentage. Education rated from 1 (primary school) to 7 (university degree)

$B M I$ Body mass index in kilograms per square meter
Table 2 Success and complication rate through time, $n=77$

\begin{tabular}{llll}
\hline & Complications & $\begin{array}{l}\text { Success } \\
\text { rate }^{\mathrm{a}}\end{array}$ & Response $^{\mathrm{b}}$ \\
\hline First quartile & 2 & $41.2 \%(7 / 17)$ & $17 / 19=89 \%$ \\
Second quartile & 2 & $50.0 \%(6 / 12)$ & $12 / 19=63 \%$ \\
Third quartile & 2 & $42.9 \%(6 / 14)$ & $14 / 19=74 \%$ \\
Fourth quartile & 0 & $42.9 \%(6 / 14)$ & $14 / 20=70 \%$ \\
Total & 6 & $\begin{array}{c}\text { Mean, 44.0\% } \\
(25 / 57)\end{array}$ & $\begin{array}{c}\text { Total, } 57 \\
\text { patients }\end{array}$ \\
\hline
\end{tabular}

Patients divided in quartiles $(77 / 4=19$ patients per quartile, 20 in the fourth), chronological order

${ }^{\text {a }}$ Patient not experiencing any amount of leakage 1 year after surgery

${ }^{\mathrm{b}}$ Response after 1 year

The final part of the questionnaire discussed the distress caused by the incontinence and the impact on everyday functioning using the IIQ (five subcategories). Three out of the five items were significantly improved after 1 year, indicating a decrease in distress caused by SUI. The DDI showed as expected no differences pre- and post-surgery. The sexuality part (PIS-Q SF, not shown in a table) did not show any relevant differences pre- and post-operatively.

No differences were found in baseline characteristics between the "success" and "failure" patients (Table 5). However, it was found that a BMI of 35 or higher was negatively related to the success rate of the MiniArc (Table 6).

\section{Discussion}

This prospective single-center study was designed to evaluate the efficacy, safety and impact on quality of life of the MiniArc procedure in women with SUI. Of the 57 evaluated patients, after 1 year, $32(56 \%)$ stated again or still experiencing SUI, thus indicating failure of the

Table 3 PGI-I, 1 year post-surgery

\begin{tabular}{lll}
\hline Very much better & $16(\mathrm{D}=13,3=\mathrm{ND})$ & $(28 \%)$ \\
Much better & $23(\mathrm{D}=11, \mathrm{ND}=12)$ & $(40 \%)$ \\
A little better & $10(\mathrm{D}=1, \mathrm{ND}=9)$ & $(17.5 .5 \%)$ \\
No difference & $6(\mathrm{D}=0, \mathrm{ND}=6)$ & $(10.5 .5 \%)$ \\
A little worse & 0 & \\
Much worse & $1(\mathrm{D}=0, \mathrm{ND}=1)$ & $(2 \%)$ \\
Very much worse & $1(\mathrm{D}=0, \mathrm{ND}=1)$ & $(2 \%)$ \\
Total & 57 \\
Dry (success) & $25(44 \%)$ \\
Not dry (failure) & $32(56 \%)$ & \\
\hline
\end{tabular}

Values are given as mean $\pm \mathrm{SD}$

$D$ dry, $N D$ not dry 
Table 4 Comparison of pre- and post-operational scores of patients treated with the MiniArc, $p<0.05=$ significant

\begin{tabular}{|c|c|c|c|}
\hline & Pre-operational, $n=77$ & 1 -year, $n=57$ & $p$ value $^{\mathrm{b}}$ \\
\hline QoL scale $[1-6]$ & $4.6 \pm 0.9$ & $4.9 \pm 1.0$ & ns \\
\hline EQ-5D & $0.82 \pm 0.19$ & $0.86 \pm 0.19$ & ns \\
\hline VAS & $73.8 \pm 17.2$ & $77.3 \pm 13.3$ & ns \\
\hline \multicolumn{4}{|c|}{ Incontinence-related distress (UDI) } \\
\hline Discomfort/pain & $26.6 \pm 23.9$ & $13.2 \pm 20.1$ & $0.009^{\mathrm{a}}$ \\
\hline Urinary incontinence & $58.9 \pm 24.1$ & $23.4 \pm 25.0$ & $0.000^{\mathrm{a}}$ \\
\hline Overactive bladder & $30.7 \pm 24.6$ & $13.7 \pm 18.7$ & $0.000^{\mathrm{a}}$ \\
\hline Obstructive micturition & $26.2 \pm 24.8$ & $17.0 \pm 23.3$ & $0.024^{\mathrm{a}}$ \\
\hline Genital prolapse & $8.4 \pm 15.9$ & $3.8 \pm 10.0$ & $0.000^{\mathrm{a}}$ \\
\hline \multicolumn{4}{|c|}{ Impact on everyday functioning (IIQ) } \\
\hline Mobility & $50.7 \pm 18.9$ & $40.0 \pm 18.4$ & $0.003^{\mathrm{a}}$ \\
\hline Emotional & $49.9 \pm 18.3$ & $37.1 \pm 14.7$ & $0.000^{\mathrm{a}}$ \\
\hline Physical & $40.2 \pm 16.1$ & $32.6 \pm 12.6$ & ns \\
\hline Social & $34.3 \pm 13.2$ & $29.6 \pm 10.7$ & $\mathrm{~ns}$ \\
\hline Embarrassment & $53.0 \pm 21.6$ & $41.0 \pm 17.9$ & $0.006^{\mathrm{a}}$ \\
\hline \multicolumn{4}{|c|}{ Defecation disorders (DDI) } \\
\hline Constipation & $11.2 \pm 19.8$ & $9.4 \pm 15.8$ & $\mathrm{~ns}$ \\
\hline Painful defecation & $9.3 \pm 18.0$ & $7.3 \pm 15.8$ & $\mathrm{~ns}$ \\
\hline Fecal incontinence & $7.1 \pm 16.8$ & $7.6 \pm 16.4$ & $\mathrm{~ns}$ \\
\hline Flatus incontinence & $18.6 \pm 25.7$ & $23.4 \pm 26.0$ & $\mathrm{~ns}$ \\
\hline
\end{tabular}

Values are given as mean $\pm \mathrm{SD}$. The $p$ values were Bonferroni corrected. Scale from 1 (no complaints) to 100 (a lot of complaints). $p$ value, preoperative compared to 1 -year post-operative $(n=57)$

QoL Quality of life from 1 (very bad) to 6 (excellent), VAS Visual Analog Scale (1-100), EQ-5D EuroQol-5 Dimensions, ns not significant

${ }^{\text {a }}$ Statistically significant

${ }^{\mathrm{b}}$ Paired-samples $T$ test, UDI, IIQ, and DDI

MiniArc. After 1 year, the PGI-I showed an improvement in $68 \%$ of the patients (Table 3 ).

Following surgery, an improvement was seen in everyday functioning, as well as a significant drop in incontinencerelated distress. The DDI part of the questionnaire did not show any significant improvements but was not specifically associated with SUI. For the significant change in the subcategory "genital prolapse" of the UDI, no explanation could be found, but the improvement could be accredited to a decrease of complaints in general.
Complications were seen in 6 of 77 patients (8\%). The rate of complications and success did not show any significant improvement in time (Table 2). There are certain limitations of this study that need to be addressed.

At present there is an ongoing discussion about the amount of compression with which the mini-slings should be positioned against the urethra. Up to now, no consensus seems to be reached about a standardized method to place these mini-slings as effective as possible. Because all the surgeries in this study were performed by one gynecologist
Table 5 Clinical characteristics of failures versus success 1 year after MiniArc $(n=57), p<0.05=$ significant

Values are given as mean $\pm \mathrm{SD}$ or percentage. Education rated from 1 (primary school) to 7 (university degree)

$B M I$ Body mass index in kilograms/square meter

${ }^{a}$ Independent-samples $T$ test

\begin{tabular}{llll}
\hline & Success $($ dry $)(n=25)$ & $\begin{array}{l}\text { Failure }(\text { not dry) } \\
(n=32)\end{array}$ & $p$ value $^{\mathrm{a}}$ \\
\hline Age & $52.0 \pm 12.0($ range, $36-79)$ & $56.0 \pm 13.5$ (range, $29-80)$ & 0.248 \\
BMI & $27.2 \pm 4.1($ range, $19.5-33.5)$ & $29.70 \pm 7.6$ (range, 17.9-50.4) & 0.122 \\
Parity & $2.0 \pm 0.8$ & $2.3 \pm 1.0$ & 0.200 \\
None & $1(4 \%)$ & $1(3 \%)$ & \\
$1-3$ & $23(92 \%)$ & $29(91 \%)$ & 0.309 \\
$>4$ & $1(4 \%)$ & $2(6 \%)$ & \\
Education & $3.7 \pm 1.7$ & $3.3 \pm 1.7$ & \\
\hline
\end{tabular}


Table 6 Sub-categorical success and improvement rates 1-year post-surgery

\begin{tabular}{|c|c|c|c|c|c|c|}
\hline \multirow[b]{2}{*}{ Complete population } & \multicolumn{2}{|l|}{ Success (dry) } & \multicolumn{3}{|l|}{ Success (dry) } & \multirow{2}{*}{$\frac{p \text { value }^{\mathrm{a}}}{0.000^{\mathrm{b}}}$} \\
\hline & $44 \%(n=57)$ & vs. & $\mathrm{BMI} \geq 35 \mathrm{~kg} / \mathrm{m}^{2}$ & $(n=7)$ & $0 \%$ & \\
\hline Complete population & $44 \%(n=57)$ & vs. & Age $\geq 65$ years & $(n=15)$ & $33 \%$ & 0.347 \\
\hline \multirow[t]{2}{*}{ Complete population } & $44 \%(n=57)$ & vs. & Parity $\geq 3$ & $(n=14)$ & $40 \%$ & 0.181 \\
\hline & Improved & & Improved & & & $p$ value $^{\mathrm{b}}$ \\
\hline Complete population & $86 \%(n=57)$ & vs. & $\mathrm{BMI} \geq 35 \mathrm{~kg} / \mathrm{m}^{2}$ & $(n=7)$ & $57 \%$ & $0.023^{\mathrm{a}}$ \\
\hline Complete population & $86 \%(n=57)$ & vs. & Age $\geq 65$ years & $(n=15)$ & $73 \%$ & 0.200 \\
\hline Complete population & $86 \%(n=57)$ & vs. & Parity $\geq 3$ & $(n=14)$ & $86 \%$ & 0.368 \\
\hline
\end{tabular}

Values are given as percentages

$B M I$ Body mass index, Improved as stated in questionnaire (independent of success)

${ }^{a}$ Independent-samples $T$ test

${ }^{\mathrm{b}}$ Statistically significant

(IMC), this could partly explain the lower success rate. However, the gynecologist that performed the surgery is an experienced specialist in MUS surgery, as well as an AMStrained instructor for the placement of the MiniArc. Nevertheless, we recommend this study to be repeated in a multicenter setting using comparative patient groups.

The second limitation is the subjective definition of failure in this study. This subjective measurement, however, does provide information about the experience of the patient over a longer period of time. So, despite the fact that clinical tests after 1 year (Cough Stress Test (CST), pad test, urodynamic investigation) would have guaranteed objectivity, these investigations would merely reflect a measurement at one point in time. We therefore feel that our definition of cure (and failure) is valid to use.

Thirdly, it is possible that a misinterpretation of the questions regarding the different types of incontinence could have resulted in inaccurate results. At least part of the patients indicating persistent SUI after 1 year could be in fact experiencing (de novo) urge incontinence. Although we feel that the question in the UDI regarding SUI is clear, clinical tests will be needed to further validate the results and exclude a possible bias.
The major advantage of this study is that multiple questionnaires were used to assess the different improvement or deterioration aspects post-surgery. According to the International Continence Society and the International Consultation on Incontinence, the UDI and the IIQ are recommended as grade A-condition specific questionnaires to be used in research [23].

Furthermore the PGI-I and the PIS-Q are recommended by the International Urogynecological Association as validated SUI outcome measures [24]. The extensiveness and many different aspects of the questionnaires should make this study valid to offer urologists and gynecologists reliable information.

Due to the fact that prior to the first included patient, our gynecologist had only performed five MiniArc interventions, a learning curve was expected. However, upon analyzing the success and failure rates, no improvement in cure and complication rate was found (Table 2). The absence of a learning curve should lead to more reliable and valid results.

For our comparison with other studies, a literature research was conducted in PubMed ${ }^{\circledR}$ using the terms "SUI" and "MiniArc." The found studies for the MiniArc showed success rates ranging from $69 \%$ to $91 \%(11,12$, 14-17) and are visualized in Table 7. Our 1-year analysis

Table 7 Other MiniArc studies ranked by number of patients

\begin{tabular}{lcclc}
\hline Study & Number of patients & Success rate (percentage) & Definition of success & Follow-up \\
\hline Kennelly, MJ, et al. [15] & 188 & 90.6 & Negative CST & 1 year \\
Jiménez Calvo J, et al. [14] & 135 & 91.9 & Negative CST & S95 days (mean) \\
Pickens RB et al. [18] & 120 & $93.5^{\text {a }}$ & Subjective: no leakage & 1 year \\
Hogewoning, CRC, et al. ${ }^{\text {a }}$ & 77 & $44^{\text {a }}$ & Subjective: no leakage & 1 year \\
De Ridder, D, et al. [11] & 75 & 85 & Negative CST & 1 year \\
Debodinance, P, et al. [12] & 72 & 69.1 & Negative CST & Negative CST \\
Moore, RD, et al. [16] & 61 & 91.4 & Subjective: no leakage & 1 year \\
Sottner, O et al. [17] & 38 & $76.7^{\text {a }}$ & months \\
\hline
\end{tabular}

${ }^{\text {a }}$ No objective outcome measures 
showed different results with a success rate as low as $44 \%$. It is clear that the success rate of our study is exceptionally low, but two other studies (Sottner et al. [17] and Debodinance et al. [12]) also present low rates of success.

Variances between subjective and objectives outcomes are common in literature, but results are conflicting [2529]. No statement can be made whether subjective success rates deviate from objective ones in either a negative or positive way. Future research should include both objective and subjective measurements that can then be either analyzed separately or combined.

Characteristics of the patient population could also partly explain the disappointing success rate. In this study, no restrictions were made based on the severity of SUI and BMI whereas certain others leave out patients with a BMI $>35 \mathrm{~kg} / \mathrm{m}^{2}$. The differences between the "success" and "failure" population are visualized in Table 5 and do not show any significant differences in clinical characteristics. If the population is further subdivided in specific categories (Table 6), it is shown that a BMI of $35 \mathrm{~kg} / \mathrm{m}^{2}$ or more is an indication for a lower success rate, but higher age $(\geq 65)$ or a higher number of parities $(\geq 3)$ is not related to lower rates of success. Improvement rates in Table 6 also show that a $B M I \geq 35 \mathrm{~kg} / \mathrm{m}^{2}$ is a significant negative factor in this research population.

The 20 patients $(26 \%)$ that were lost to follow-up could play a significant part in the accuracy of the evaluation as well, although their characteristics did not show any differences from the participating group.

\section{Conclusion}

The 1-year follow-up of the anti-incontinence treatment using the MiniArc single incision sling revealed a high rate of failure (56\%), while showing improvement in $68 \%$.

Acknowledgments This study was initiated by the Pelvic Floor \& Sexuality Research Group Leiden. We would like to thank Dr. J.P.W. $\mathrm{R}$. Roovers for carefully reading the manuscript.

Conflict of interest Dr. I.M.C. Ruhe is an AMS-trained instructor for the placement of the MiniArc.

Open Access This article is distributed under the terms of the Creative Commons Attribution Noncommercial License which permits any noncommercial use, distribution, and reproduction in any medium, provided the original author(s) and source are credited.

\section{References}

1. Chiarelli P, Brown W, McElduff P (1999) Leaking urine: prevalence and associated factors in Australian women. Neurourol Urodyn 18(6):567-577
2. Moller LA, Lose G, Jorgensen T (2000) The prevalence and bothersomeness of lower urinary tract symptoms in women 40 60 years of age. Acta Obstet Gynecol Scand 79(4):298-305

3. Simeonova Z, Milsom I, Kullendorff AM, Molander U, Bengtsson C (1999) The prevalence of urinary incontinence and its influence on the quality of life in women from an urban Swedish population. Acta Obstet Gynecol Scand 78(6):546-551

4. Abrams P, Cardozo L, Fall M, Griffiths D, Rosier P, Ulmsten U, Van KP, Victor A, Wein A (2002) The standardisation of terminology of lower urinary tract function: report from the Standardisation Sub-committee of the International Continence Society. Am J Obstet Gynecol 187(1):116-126

5. Grimby A, Milsom I, Molander U, Wiklund I, Ekelund P (1993) The influence of urinary incontinence on the quality of life of elderly women. Age Ageing 22(2):82-89

6. Hunskaar S, Vinsnes A (1991) The quality of life in women with urinary incontinence as measured by the sickness impact profile. $\mathrm{J}$ Am Geriatr Soc 39(4):378-382

7. Shumaker SA, Wyman JF, Uebersax JS, McClish D, Fantl JA (1994) Health-related quality of life measures for women with urinary incontinence: the Incontinence Impact Questionnaire and the Urogenital Distress Inventory. Continence Program in Women (CPW) Research Group. Qual Life Res 3(5):291-306

8. van der Vaart CH, de Leeuw JR, Roovers JP, Heintz AP (2002) The effect of urinary incontinence and overactive bladder symptoms on quality of life in young women. BJU Int 90 (6):544-549

9. van der Vaart CH, de Leeuw JR, Roovers JP, Heintz AP (2003) Measuring health-related quality of life in women with urogenital dysfunction: the urogenital distress inventory and incontinence impact questionnaire revisited. Neurourol Urodyn 22(2):97104

10. Latthe PM, Foon R, Toozs-Hobson P (2007) Transobturator and retropubic tape procedures in stress urinary incontinence: a systematic review and meta-analysis of effectiveness and complications. BJOG 114(5):522-531

11. De RD, Berkers J, Deprest J, Verguts J, Ost D, Hamid D, Van der Aa F (2010) Single incision mini-sling versus a transobutaror sling: a comparative study on MiniArc and Monarc slings. Int Urogynecol J Pelvic Floor Dysfunct 21(7):773-778

12. Debodinance P, Delporte P (2009) MiniArc: preliminary prospective study on 72 cases. J Gynecol Obstet Biol Reprod (Paris) 38 (2):144-148

13. Gauruder-Burmester A, Popken G (2009) The MiniArc sling system in the treatment of female stress urinary incontinence. Int Braz J Urol 35(3):334-341

14. Jimenez CJ, Hualde AA, Cebrian Lostal JL, Alvarez BS, Jimenez PJ, Montesino SM, Raigoso OO, Lozano UF, Pinos PM, Gonzalez de Garibay AS (2010) Stress urinary incontinence surgery with MiniArc swing system: our experience. Actas Urol Esp 34 (4):372-377

15. Kennelly MJ, Moore R, Nguyen JN, Lukban JC, Siegel S (2010) Prospective evaluation of a single incision sling for stress urinary incontinence. J Urol 184(2):604-609

16. Moore RD, Mitchell GK, Miklos JR (2009) Single-center retrospective study of the technique, safety, and 12-month efficacy of the miniarc single-incision sling: a new minimally invasive procedure for treatment of female SUI. Surg Technol Int 18:175-181

17. Sottner O, Halaska M, Maxova K, Vlacil J, Kolarik D, Chaloupecky J, Hurt K, Zahumensky J, Zmrhalova B, Vojtech J (2010) New Single-Incision Sling System MiniArc in treatment of the female stress urinary incontinence. Ceska Gynekol 75(2):101104

18. Pickens RB, Klein FA, Mobley JD III, White WM (2010) Single Incision Mid-urethral Sling for Treatment of Female Stress Urinary Incontinence. Urol 77:321-324 
19. (No authors listed) (1990) EuroQol—a new facility for the measurement of health-related quality of life. The EuroQol Group. Health Policy 16(3):199-208

20. Roovers JP, van der Bom JG, Huub VDV, Fousert DM, Heintz AP (2001) Does mode of hysterectomy influence micturition and defecation? Acta Obstet Gynecol Scand 80(10):945-951

21. Rogers RG, Coates KW, Kammerer-Doak D, Khalsa S, Qualls C (2003) A short form of the Pelvic Organ Prolapse/Urinary Incontinence Sexual Questionnaire (PISQ-12). Int Urogynecol J Pelvic Floor Dysfunct 14(3):164-168

22. Yalcin I, Bump RC (2003) Validation of two global impression questionnaires for incontinence. Am J Obstet Gynecol 189(1):98 101

23. Castillo PA, Espaillat-Rijo LM, Davila GW (2010) Outcome measures and definition of cure in female stress urinary incontinence surgery: a survey of recent publications. Int Urogynecol J Pelvic Floor Dysfunct 21(3):343-348

24. Ghoniem G, Stanford E, Kenton K, Achtari C, Goldberg R, Mascarenhas T, Parekh M, Tamussino K, Tosson S, Lose G, Petri E (2008) Evaluation and outcome measures in the treatment of female urinary stress incontinence: International Urogynecological Association (IUGA) guidelines for research and clinical practice. Int Urogynecol J Pelvic Floor Dysfunct 19 (1):5-33

25. Deffieux X, Donnadieu AC, Porcher R, Gervaise A, Frydman R, Fernandez $H$ (2007) Long-term results of tension-free vaginal tape for female urinary incontinence: follow up over 6 years. Int J Urol 14(6):521-526

26. Holmgren C, Nilsson S, Lanner L, Hellberg D (2005) Long-term results with tension-free vaginal tape on mixed and stress urinary incontinence. Obstet Gynecol 106(1):38-43

27. Zugor V, Labanaris AP, Rezaei-Jafari MR, Hammerer P, Dembowski J, Witt J, Wucherpfennig W (2010) TVT vs. TOT: a comparison in terms of continence results, complications and quality of life after a median follow-up of 48 months. Int Urol Nephrol 42:915-920

28. Deval B, Ferchaux J, Berry R, Gambino S, Ciofu C, Rafii A, Haab F (2006) Objective and subjective cure rates after transobturator tape (OBTAPE) treatment of female urinary incontinence. Eur Urol 49(2):373-377

29. Giberti C, Gallo F, Cortese P, Schenone M (2007) Transobturator tape for treatment of female stress urinary incontinence: objective and subjective results after a mean follow-up of two years. Urology 69(4):703-707 